\title{
A medicalização da educação e da resistência no presente: disciplina, biopolítica e segurança
}

\author{
Flávia Cristina Silveira Lemos \\ Universidade Federal do Pará - PA
}

\section{Resumo}

Este artigo visa colocar em debate a medicalização intensiva da existência verificada na atualidade, sobretudo quando esta ocorre pelo silenciamento da resistência, seja pelas disciplinas, seja pelas biopolíticas seja ainda pelas estratégias de segurança. Estas são cada vez mais refinadas, sendo utilizadas de modo tático, em um conjunto de instituições que são administradas por especialistas peritos em diagnosticar os desvios sociais e as divergências pelas racionalidades biomédicas, psicologizantes e patologizantes da educação inventiva e da dissidência política. O objetivo deste artigo é problematizar essas práticas sociais e seus efeitos cotidianos, além de descrever e analisar as resistências a essas práticas, sempre com base nas contribuições de Michel Foucault e de Robert Castel. Esse texto, em formato de estudo teórico, é um recorte de pesquisas em andamento, de cunho documental e histórico, em que pretendemos contribuir com a crítica à medicalização da educação e da dissidência política, na atualidade, em uma sociedade de segurança.

Palavras-chave: Medicalização; disciplina; biopolítica.

\section{Nowaday's medicalization of Education and resistance : discipline, biopolitics and security}

\begin{abstract}
This article aims at bringing to debate nowaday's intensive medicalization of existence, especially when it occurs by silencing of resistance by both disciplines and biopolitical and also by the strategies of increasingly refined security. These are used tactically, in a set of institutions that are run by expert specialists in diagnosing social deviations and differences by biomedical rationales, psychologizing and pathologizing of inventive education and political dissent. Our aim in this work is to problematize these everyday social practices and their effects. We also propose to describe and analyze the resistance to these practices. To sustain our argument we have the theoretical support of Michel Foucault and Robert Castel. This study is part of and ongoing research and historical nature through which we intent to contribute to the critique of medicalization of education and political dissent, today, in a society of security.
\end{abstract}

Keywords: Medicalization; Discipline; Biopolitics.

\section{La medicalización de la educación y de la resistencia en el presente: disciplina, biopolítica y seguridad}

\section{Resumen}

Este artículo tiene por objetivo poner en tela de juicio la medicalización intensiva de la existencia verificada en la actualidad, principalmente cuando ésta sucede por el silenciamiento de la resistencia, sea por las disciplinas, sea por las biopolíticas sea aún por las estrategias de seguridad. Éstas son cada vez más refinadas, siendo utilizadas de modo táctico, en un conjunto de instituciones que son administradas por especialistas peritos en diagnosticar los desvíos sociales y las divergencias por las racionalidades biomédicas, psicologizantes y patologizantes de la educación inventiva y de la disidencia política. El objetivo de este artículo es problematizar esas prácticas sociales y sus efectos cotidianos, además de describir y analizar las resistencias a esas prácticas, siempre con base en las contribuciones de Michel Foucault y de Robert Castel. Ese texto, en formato de estudio teórico, es un recorte de investigaciones y andamiento, de cuño documental e histórico, en que se pretende contribuir con la crítica a la medicalización de la educación y de la disidencia política, en la actualidad, en una sociedad de seguridad.

Palabras-clave: medicalización; disciplina; biopolítica. 


\section{Introdução}

Este artigo visa pensar a intensificação das práticas medicalizantes das resistências políticas e da educação na sociedade contemporânea por meio da análise de alguns acontecimentos da atualidade. A produção das dissidências tem sido alvo de processos de desqualificação pela intervenção médico-psiquiátrica, sendo patologizada e/ou normalizada, de acordo com os estudos de Foucault (2004), no curso "O poder psiquiátrico".

Por exemplo, a resistência a um processo de escolarização padronizado que nega a diferença pode ser patologizada se for classificada como sintoma de um transtorno de oposição desafiadora ou ainda como traço de infantilidade advindo de supostas carências de uma família qualificada como disfuncional. Poderíamos trazer outros acontecimentos em que, na sociedade atual, a contestação de um modelo e de uma norma passa a ser classificada como transtorno e perigo.

Assim, pretendemos nesse artigo colocar em debate a medicalização das resistências na sociedade contemporânea e descrever alguns de seus efeitos no controle dos corpos, seja este por medicamento, pela internação ou pelo processo de normalização terapêutica.

A medicalização, nesse texto, é definida como uma maneira de produzir uma racionalidade simplista, que se reduz a um conjunto de práticas sociais, culturais, históricas, econômicas, subjetivas e políticas com vista a submetê-las a relações lineares de causa e efeito médico-biológicas, médico-psicológicas, neuropedagógicas entre outras análises de causa e efeito que resultem em patologização das condutas desviantes.

Ademais, a medicalização não se restringe à patologização, pois também pode operar a antecipação da gestão preventiva da saúde, em termos de governo de riscos e vulnerabilidades por dispositivos biopolíticos, disciplinares e de segurança normalizadores que não patologizam, e sim, administram perfis, potencializam performances e ampliam habilidades e a produtividade. Nesse aspecto, é bem mais sutil o processo de medicalização da vida e da educação, pois este passa a ocorrer em nome da saúde como promessa de promoção e não como tratamento, acionando práticas educativas consideradas democráticas. Os trabalhos de Robert Castel (1987) ressaltaram esses mecanismos e refinamentos dos controles sociais medicalizantes como contribuições relevantes para nossa atualidade.

Nas últimas décadas o desvio das normas sociais tem sido psiquiatrizado rapidamente e de modo cada vez mais intenso. De acordo com os estudos de Foucault (1988, 1999), em qualquer lugar, olhares vigilantes e examinadores enquadram os atos que escapam das médias em um espectro disciplinar e biopolítico.

Desobedecer normas se tornou um problema político a ser governado no campo da saúde na interface com a educação, a assistência social e a segurança. A polícia médica, em composição com as outras polícias da saúde e com uma série de outras práticas semelhantes, gera efei- tos de medicalização refinados e generalizados em nome do aumento da longevidade, do governo da saúde, da produção acelerada e ampliada nos estudos e no trabalho, de melhora das performances sexuais e físicas, de estimulação cognitiva com promessas de maior concentração em provas e concursos, etc.

Por meio de racionalidades medicalizantes, o crescente mercado da saúde, da educação e da segurança encontra na normalização um mecanismo de silenciamento da produção da diferença e de controle de qualquer prática de resistência civil na sociedade contemporânea. A medicalização terapêutica e a autoritária se coadunam na tentativa de diminuir resistências e docilizar corpos em nome da lei e da ordem social. As vidas passam a ser anestesiadas e impedidas de qualquer plano de questionamento das práticas cristalizadas e instituídas que visam domesticá-las.

Neste contexto, este artigo se propõe a fazer uma análise teórica da medicalização da resistência como um recorte de uma pesquisa maior ainda em andamento, desenvolvida com o apoio do CNPq, a respeito da medicalização nas práticas do Fundo das Nações Unidas para a Infância brasileira. Fazemos um recorte bem-delimitado desse projeto e apresentamos ao leitor uma reflexão teórica que, em nossa avaliação, é relevante, pois pode contribuir para outros trabalhos que analisam práticas de medicalização que não apenas as realizadas pelos organismos multilaterais.

O texto também traz elementos analíticos de nossa participação no programa de pós-graduação em educação e no programa de pós-graduação em Psicologia, UFPA bem como a experiência de ter sido membro no Conselho Federal de Psicologia (gestão 2011-2013). Também apresenta aspectos referentes à nossa presença nos debates do Fórum sobre Medicalização da Educação e da Sociedade e nos congressos da Associação Brasileira de Psicologia Escolar e Educacional (ABRAPEE). Por fim, traz nossa experiência de atuação com a crítica à judicialização da vida e com a educação em direitos humanos como docente de Psicologia Social e de Análise Institucional, da UFPA e como estudiosa, ao longo dos últimos vinte anos, dos trabalhos de Michel Foucault e de Robert Castel.

Assim, pretendemos com este artigo oferecer pistas aos leitores e interessados, teórica e politicamente, no tema da medicalização e da resistência, visando contribuir para um debate sobre esse tema, no cenário nacional e internacional, que seja cada vez mais denso e importante no plano ético de nossos posicinamentos de crítica do presente.

\section{Mecanismos disciplinares e a medicalização da educação e das resistências}

Na lógica disciplinar, cada ato é meticulosamente governado por um conjunto de táticas e exercícios, repetidos e efetuados em inúmeras instituições fechadas, mas também em meio aberto, com as contenções medicamentosas, por exemplo, que operam sem muros de concreto, mas construem outros tipos de repartição social. A sociedade disci- 
plinar surgiu a partir das últimas décadas do século XVII e se tornou uma tecnologia de subjetivação que aciona as práticas educativas na família e na escola, as quais se materializam no trabalho, na atuação política, nos equipamentos de seguridadee segurança, etc.

Para Michel Foucault (1999), as disciplinas são técnicas que visam forjar corpos úteis e dóceis, trabalhados por meio de rituais de verdade e de poder microfísico, em relações de encadeamento permanente de ação sobre ação e em uma combinação de forças múltiplas que produzem um modo individual de ser - esquadrinhado e constituído por exercícios regulares e meticulosos de disciplinamento.

O repúdio ao castigo físico e a incitação à repetição das condutas estabelecidas como modelos para cada situação ganham relevância nesta sociedade disciplinar. $\mathrm{Na}$ escola, na família, no local de trabalho, no hospital, no exército e em tantos outros meios ou equipamentos sociais, e mesmo nos espaços abertos, as tecnologias disciplinares são usadas para dispersar as revoltas e ampliar a educação para a produtividade e submissão política (Foucault, 1999).

Para Foucault $(1979,1999)$, quando as cidades começam a aparecer e crescer, a partir do momento em que o capitalismo industrial passa a demandar força de trabalho obediente, a escola surge como instituição obrigatória de educação para a ordem e o progresso e o Estado emerge como regulador social, policiaando as condutas. Qualquer ameaça a esta nova organização estatizante e liberal de viver, qualquer impedimento a uma subjetividade consumidora e empreendedora de ser anestesiante e que comercialize objetos fetiches em formato de pílulas ilusórias de felicidade e normalização - passa a ser perseguida politicamente pela prevenção educativa de gestão de riscos com as tecnologias de polícia médica e com as medidas higienistas e de internação mais autoritárias.

Os saberes chancelados pela ciência vão sendo cada vez mais acionados instrumentalmente para governar corpos, com vistas ao desenvolvimento dos países em concorrência no liberalismo, e os movimentos de multidão, que poderiam provocar subversão e questionamentos desta nova ordem social, tornam-se regulados preventivamente pela apropriação das táticas normalizantes da sociedade, como, por exemplo, as disciplinares (Foucault, 1979, 1999, 2008b).

A formação detalhada dos corpos para a submissão política e a expansão de habilidades de produção se tornam um imperativo a se realizar pelo controle dos corpos no tempo, no espaço, pelo exame, pela vigilância hierárquica e pela sanção normalizadora. Todas estas estratégias disciplinares ganham evidência e importância social e se tornam utilitaristas no liberalismo nascente, tanto na esfera econômica quanto na política, ao longo dos séculos $X I X, X X$ e $X X I$, acirradas especialmente nas últimas décadas do século $X X$ e início do XXI.

Por isto Foucault (2008b) declara que o liberalismo é um estilo de vida, e não apenas um regime político e econômico. Lembremos que é nesse período que as revoluções francesa, norte-americana e inglesa apregoam os ideais de direitos civis e políticos, bem como os direitos sociais, tendo a liberdade como âncora desde que opere juntamente com o trabalho moralizante e a educação civilizadora. Em tal regime, uma condição para a liberdade é a disciplina dos corpos, direitos com deveres, no plano da produção do sujeito de direitos individualizado e docilizado. Neste aspecto, Foucault (1999) destaca que as revoluções que inventaram as liberdades também criaram as disciplinas.

A ideia de civilização e de educação civilizadora para impedir a barbárie se torna substancial como projeto dessa nova sociedade, que deseja romper, pelo lluminismo, com um passado que passa a considerar como de trevas, de hábitos primitivos e rústicos, a serem superados pela ordem normativa e normalizadora, ou seja, pela lei e pela ordem. Refinar condutas e educar para hábitos civilizados passa a ser uma prática cultural e social, aliada às demandas políticas e econômicas do capitalismo concorrencial, da industrialização, da escolarização obrigatória liberal republicana, da família nuclear burguesa retraída à privacidade, da polícia da saúde normalizante e da vida na cidade regulada pela ordem medicalizada e pelo legalismo do direito positivista.

Diante das tentativas de maximização de uma educação disciplinar moduladora de cada conduta, capitalizam-se e hipervalorizam-se técnicas de formação normativa e normalizadora dos corpos. No bojo desse projeto, a indisciplina se torna um problema político a governar, a punir, a prevenir e a corrigir por tecnologias disciplinares educativas e reeducativas (Foucault, 1999).

A indisciplina, ao mesmo tempo, passa a ser uma forma de subverter o controle normalizador como resistência à obediência docilizadora. $\mathrm{O}$ corpo indisciplinado começa a ser rotulado como anormal, como o avesso do que se espera e do que se deseja constituir para a produção capitalista. Este corpo que rejeita o esquadro e a medida, que não aceita ser modelado e governado por regras normalizadoras, passa a ser alvo de castigos que operam por mais exercícios disciplinares, com o aumento de estratégias de controle terapêutico, socioeducativo, assistencial corretivo e securitário-segregativo. Praticamente todas estas táticas são atravessadas pelos processos medicalizantes moduladores da gestão de risco, da gerência disciplinar e da fabricação de performances de ordem e produção.

Assim como os livros de ocorrência nas escolas, os dossiês dos conselhos tutelares, os escritos arquivados nos abrigos e nos equipamentos de internação de jovens e adultos e os boletins de ocorrências das delegacias, os registros e prontuários das instituições modernas se tornam espaços de visibilidade dessa disciplina. Quanto mais indisciplinado for um corpo mais disciplina ele receberá como punição, é o que Foucault denominou de sanção normalizadora (Foucault, 1999).

Ao ser examinado e vigiado, cada um de nós é também avaliado quanto à obediência às normas. $O$ tribunal medicalizante/normalizador efetuará uma contabilidade penal e encaminhará os indisciplinados para espaços em que recebam mais controle social e/ou recomendará medicações disciplinadoras e tratamentos com uma variedade de 
profissionais de saúde que atuem com técnicas adaptativas/ disciplinares. A resistência é classificada como transtorno, podendo-se ter como um exemplo o vem sendo hoje designado nos manuais de psiquiatria de transtorno de oposição desafiadora. Hoje, professores que lutam são etiquetados como portadores da Síndrome de Burnout, por resistirem às péssimas condições de trabalho nas escolas e universidades; alunos classificados como indisciplinados são enviados pela escola aos conselhos tutelares, e, por sua vez, os conselheiros tutelares os encaminham para psicólogos e para os médicos neurologistas e psiquiatras, em unidades de saúde e hospitais.

Corpos inquietos podem ser chamados de ansiosos e/ou de portadores de Transtorno de Déficit de Atenção e Hiperatividade. Mulheres que resistem são designadas como histéricas e ativistas de movimentos sociais são nomeados como doentes mentais. Além destas, poderíamos listar inúmeras situações em que os transtornos psiquiátricos passaram a se enquadrar e para os quais a indústria farmacêutica passou a vender seus kits de drogas psicotrópicas.

Concluindo este tópico, pensamos que se o indivíduo que recebe sanções disciplinares continuar a exercer mais indisciplina, ou seja, mais resistência, outras estratégias de ampliação da medicalização serão efetuadas, como as que acionam os mecanismos de segurança pela gestão biopolítica, em que a vida entra na história pelo cultivo da saúde atrelado aos dispositivos secundários de gerência da população.

\section{A biopolítica e a medicalização das resistências}

Foucault (1988) escreve que pela biopolítica a vida entra na história como espécie biológica e passa a ser gerida em meio à racionalidade liberal, concomitantemente ao aparecimento do mercado da saúde, forjado de maneira imanente ao crescimento do prestígio da medicina social junto ao Estado Moderno (Foucault, 1979):

Foi a vida, muito mais do que o direito, que se tornou o objeto das lutas políticas, ainda que estas últimas se formulem através de afirmações de direito. O "direito" à vida, ao corpo, à saúde, à felicidade, à satisfação das necessidades, o "direito", acima de todas as opressões ou "alienações", de encontrar o que se é e tudo o que se pode ser (Foucault, 1988, p. 136)

Na biopolítica, a medicina social pode se apresentar como racionalidade importante para o Estado Moderno governar a população como totalidade e por recortes de segmentos privilegiados, como infância, família, adolescência, adultos e idosos, por exemplo. Uma arte de gerir a saúde e regular o fazer viver e o deixar morrer é inaugurada e passa a utilizar saberes para realizar este tipo de intervenção pela informática, pela estatística, pelo território geográfico, pela economia política, pela demografia, pela medicina social, pela psicologia, pela educação, pelo direito e pela administração social (Foucault, 1988, 2008a).

A higiene e a prevenção em saúde pela educação são maneiras de generalizar o saber médico para toda a sociedade; e no caso da gestão dos riscos de adoecer, de acirrar a desobediência civil e/ou de cometer um crime, por exemplo, a atuação do Estado entra em cena com a política medicalizante, a qual, em nome da defesa da sociedade, materializa-se em um conjunto de técnicas de segurança, como a psiquiatrização das condutas, a higienização social pela escola e pela família, a limpeza da cidade pela vigilância sanitária e pela ordenação dos espaços pela polícia médica, a internação compulsória e o aprisionamento.

O poder psiquiátrico, nessa proposta de gestão da defesa da sociedade, irá cumprir uma função específica, ao se expandir em meio às tentativas de regulação da população, controlando socialmente os desvios às normas como modo de administrar para subjugar os segmentos da população (Fonseca, 2002). Afirma Foucault (2004, p. 09):

A psiquiatria, na virada entre os séculos XVIII e XIX, conseguiu sua autonomia e se revestiu de tanto prestígio pelo fato de ter podido se inscrever no âmbito de uma medicina concebida como reação aos perigos inerentes ao corpo social.

Nesse plano da política de segurança articulada à de seguridade, as práticas psiquiátricas ganharam um âmbito extremamente moralizante quando se aproximaram das lógicas racistas, no século XIX, e foram se tornando uma obra de regeneração social e controle de uma série de condições de vida, como pobreza, dificuldades na escola, intoxicação, alcoolismo, dinâmica familiar, baixa produtividade no trabaIho, resistência política, indisciplina e tantas outras.

Essas intervenções se tornaram cada vez mais medicalizantes das condutas que divergiam das normas e materializaram desobediência civil e que permitiram aos psiquiatras saírem dos asilos e estenderem suas ações para todo um amplo espectro institucional. Nesse aspecto, apresentamos uma aproximação do pensamento de Foucault com o de Castel (1987), pois ambos se detiveram na análise dessas práticas de gestão da vida por meio da crítica à noção de governo de riscos e prevenção securitária racista.

Sobre isto assim reflete Donzelot (1986, p. 118):

[...] Essa saída do psiquiatra para fora de sua reserva asilar é comandada por uma demanda imperiosa que emana dos aparelhos sociais em plena expansão que são o exército e a escola. Tornando-se gratuita e obrigatória, ela passa a ser povoada por uma massa de indivíduos insubmissos ou pouco preparados para a disciplina escolar. Suas manifestações de indisciplina, as inaptidões declaradas à aquisição escolar colocam, para os professores, problemas insuperáveis. Quais precisariam ser eliminados? Como reconhecer um idiota, um débil, uma criança que nunca poderá se adaptar à escola ou, ao contrário, outra, à qual seria suficiente um pouco de tempo e de atenção especial? 
Em 1890, a Diretoria do Ensino Primário, para superar a confusão dos professores, pede ajuda a Bourneville, alienista especializado no tratamento das crianças anormais de Salpétrière e the solicita um sistema de observações para diagnóstico e orientação dos desadaptados escolares [...].

Para Castel (1987) e para Donzelot (1986), a escola é um dos espaços em que esta lógica foi propagada na formação focada no lema "Ordem e progresso", nos contextos nascentes do liberalismo político e econômico e no das emergentes Repúblicas, com a industrialização crescente e a expansão/modernização das cidades. A saúde coletiva e mental se tornou uma demanda nas cruzadas educativas via escola, família e campanhas sanitárias; por isto, os médicos dirigiram de modo intenso suas práticas educativas às mães e às professoras normalistas, com vistas a alcançar de maneira preventiva as crianças pequenas, difundindo as ideias do movimento higienista (Boarini, 2003).

A performance na escola passou a ser avaliada por uma série de exames disciplinares, por um acompanhamento de vigilâncias hierárquicas e pela psiquiatrização - que passou a ser uma das maneiras de potencializar a disciplina pelo acréscimo da biopolítica diante do aumento das dissidências aos controles disciplinares instituídos pela escola, por exemplo. Assim, a biopolítica foi um suplemento da disciplina quando a indisciplina se intensificava e a revolta era realizada por grupos e massas.

Ao longo das primeiras décadas do século $\mathrm{XX}$ a educação escolar - cada vez mais medicalizada - passou a sustentar-se pela observação e regulação das resistências, a indisciplina começou a ser intitulada por alguns setores de especialistas como um marcador de tendências anti-sociais e a gerência das perfomances de cada educando passou a ser um problema ao mesmo tempo de saúde e de segurança. Por sua vez, além de prevenir práticas subversivas da ordem social, a educação medicalizada, em nome da segurança, foi aumentando seu espectro de intervenção, sobretudo, nas últimas décadas do século $X X$, com a emergência de uma sociedade neoliberal empreendedora que tenta comercializar cada potencial e que diminui a tolerância aos mínimos desvios sociais das normas esperadas no campo da segurança.

Assim, a medicalização biopolítica e securitária vai intensificando seu foco de governo em termos econômicos e de submissão política, passando a gerenciar o que os economistas nomeiam como capital humano. Gerir e ampliar capacidades pela educação e pela avaliação do espectro entre normalidade e anormalidade ganha visibilidade em um âmbito de preocupação social. O estudante que foge ao desempenho médio esperado pela escola e pela sociedade passa a ser chamado de criança-problema pelos médicos psiquiatras e no interior da escola (Castel 1987; Donzelot, 1986; Foucault, 2008b). Entra em cena um dispositivo racista biopolítico que atualiza as táticas disciplinares e as acopla a si: é neste sentido que a biopolítica e a disciplina são articuladas pelo biopoder e pela sociedade de segurança. Por exemplo, a higiene, baseada no racismo de sociedade e de Estado se torna uma maneira de medicalizar os corpos também para enfraquecer suas resistências e aumentar sua docilidade política, com a noção de melhoria racial pelo uso das técnicas disciplinares e biopolíticas de normalização social. É em meio a esse âmbito de debates que o pensamento darwinista social e biológico se tornou uma ferramenta no campo dos saberes e operou um deslocamento no campo científico para oferecer uma racionalidade ao racismo.

No bojo destes acontecimentos, a tática biopolítica do uso da higiene se tornou crucial para civilizar corpos e comportamentos considerados desviantes. Esta prática foi sustentada por uma racionalidade médica e sanitária, pelo neoliberalismo e pelo movimento higienista - agora reorganizado como política de saneamento dos país e do globo. Quanto mais saúde e segurança, maior seria a regulação social medicalizante, aliada a uma paralela constituição de uma população com baixo potencial de revolta.

Assim, esta gestão de capacidades ampliadas, articulada à docilidade política foi delineada em um foco biomédico e ortopédico no campo da saúde e das práticas educativas na assistência social e na política de segurança. Qualquer acontecimento que configurasse a ideia de déficit/ limites de capacidades de escolarização, de trabalho e de estabelecimento de relações humanas, passou a ser remetido à psiquiatria e ao campo dos transtornos e ao mesmo tempo as formas de resistência à docilização política foram rapidamente medicalizadas.

Castel (1987, p. 106) comenta:

A principal linha de reflexão sobre o deficiente amadureceu na tradição de uma certa forma de medicina e de psiquiatria sociais, preocupadas com problemas do trabalho, da reinserção profissional, da readaptação, da reclassificação social e da recuperação da mão-de-obra. Foi assim que o primeiro relatório na Europa sobre os problemas dos deficientes, o relatório Tominson, foi feito em 1943 numa Inglaterra que a guerra conduzia à mobilização de todas as formas de mão-de-obra possível. Se esta tradição visa a incluir mais do que excluir, ela o fez banalizando a deficiência sob a forma de um déficit que se pode compensar. A atenuação da deficiência se obtém, através dos processos de aprendizagem, que diferem profundamente da terapia.

A melhora das perfomances sociais se inscreveu nos valores de eficiência, pois é a partir delas que o desvio e a não aprendizagem se tornaram, por exemplo, uma falta a compensar por processos educativos, e neste sentido, passaram a ser reguladas, em termos de velocidade e de ritmo das performances, pela psiquiatria, pela psicobiologia, pela neuropsiquiatria infantil e pela neuropedagogia (Souza, 2010). É nesse contexto que o diagnóstico se tornou uma tecnologia de gestão diferencial das populações, de exame, de comparação e dos encaminhamentos a realizar para cada situação em que os peritos, baseados em modelos de produtividade, avaliassem como problemática para a ordem social (Castel, 1987). Explica este último autor: 
Assim se esboça a possibilidade de uma gestão previsível de perfis humanos. Até o presente, o planejamento social repousou essencialmente na definição de objetivos sócioeconômicos, a partir da programação dos equipamentos. A racionalização, a coordenação, os redesdobramentos, etc., visam a modificar a estrutura dos empreendimentos e dos estabelecimentos, com a carga para o pessoal de seguir e se adaptar a essas mudanças com todos os riscos de turbulências individuais e coletivos que comporta um tal empirismo. A programação das populações seria a contrapartida lógica de um planejamento conseqüente, mas ela é mais difícil de ser realizada por razões a um só tempo técnicas e políticas. [...] O saber médico-psicológico proporciona um código científico de objetivação das diferenças (Castel, 1987, p. 113).

Um exemplo contundente é a programação estatística dos perfis humanos de capacidade e eficiência por meio da informática, compondo diagnósticos e encaminhamentos. Nessa esfera de gerência de riscos programada forma-se um consórcio de especialistas trabalhando em rede, divididos entre os que avaliam diagnosticamente, aqueles que realizam encaminhamentos, os que atuam tratando, os que reeducam e aqueles que punem até mesmo pela medicalização do desvio, conforme afirmou Castel (1987).

Os profissionais passam a alugar seus serviços de peritos a esse setor, que é constituído de um complexo tutelar e de gestão passível de riscos, em uma versão racionalizada de competências supostamente neutras e exercidas tecnicamente em termos de administração social das condutas da população (Donzelot, 1986).

É por isto que a psiquiatria da segunda metade do século $X X$ não funcionava de forma tão limitada às instituições asilares excludentes das diferenças, pois emergiu à época uma psiquiatria mais soial, flexível e comunitária, em meio aberto, a qual foi generalizada para toda sociedade, ecom o mandato social de ser responsável por evitar os perigos ligados aos supostos riscos de certos modos de vida.

É nessa linha de intervenção que a psiquiatria se expande e passa a agir sobre a miséria, a violência, a comunicação, as moradias, a insalubridade, as famílias chefiadas por mulheres, a gravidez na adolescência, a educação nas periferias urbanas e no campo dos déficits variados, em nome da promoção da saúde e do fomento à segurança social (Castel, 1987). Essa expansão psiquiátrica aumentou sobremaneira o refinamento do controle social, constituindo na atualidade uma biossociabilidade que cada vez mais se materializa na medicalização terapêutica para alguns e autoritária para outros, dependendo da intensidade da resistência ao controle dos corpos.

O que ganhou visibilidade e apareceu é toda uma cultura psicológica de governo das relações humanas por meio de uma gerência antecipada e corretiva das condutas desviantes. Caso essas condutas sejam avaliadas conforme a indicação, a decisão poderá ser a de fazer a medicalização da resistência. No caso, trata-se do que Foucault (2008b) definiu como gestão do capital humano pelo mercado da saúde e da educação, cada vez mais capturado como campo empresarial de incitação aos investimentos calculados.

A teoria do capital humano foi criticada por Foucault no debate a respeito da biopolítica para questionar a maneira como as técnicas de gestão do comportamento humano têm sido utilizadas economicamente na lógica de investimento de cada ato como se cada corpo fosse uma empresa a zelar e a ativar em seus potenciais de mercado. Essa vertente de atenção ativou um conjunto de técnicas de governo das potencialidades visando também a desenvolvê-las ao máximo, por meio de programas baseados na construção do chamado capital humano, em que menos resistência e máxima produtividade é o mote do neoliberalismo da atualidade.

Esse processo amplia-se cada vez mais por meio da expansão de exames e de procedimentos de vigilância pautados nas normas e desvios em relação a essas normas. Computam-se em curvas os desvios-padrão da média criada como referência e, a partir de então, formulam-se políticas de compensação dos déficits e dos perigos avaliados. A norma se tornou uma tecnologia que deixou de ser substantivo e se tornou verbo (normalizar). Para tanto, utiliza a disciplina dos corpos e a biopolítica das populações, as quais, em conjunto, compõem o biopoder enquanto uma política securitária. Assim forma-se todo um dispositivo de segurança focado na gestão da anormalidade pela medicalização das resistências (Foucault, 2008).

Para Foucault (2008a) o alinhamento da disciplina com a biopolítica, compondo a estratégia de segurança, operou com os conceitos de risco e perigo, estes termos não são sinônimos. Neste contexto o risco só pode ser avaliado enquanto uma probabilidade, algo que pode acontecer; mas nada em si mesmo é um risco. O que faz um acontecimento entrar no domínio da avaliação de risco é certa política que consiste na forma como se analisa um determinado perigo.

\section{A psiquiatrização da resistência como estratégia de segurança}

A proposição do cálculo de probabilidades de risco e perigo de algo acontecer implica na materialização de uma racionalidade de segurança fundamentada na estatística como um instrumento de medida de supostas regularidades sociais fictícias e na oferta de liberdade com baixo custo de revolta social, o que só se realiza pela anestesia social operacionaliza pela medicalização como contenção química e/ou pela medicalização autoritária dos indigentes nas internações compulsórias. Assim, a segurança se organiza pela anestesia como um dispositivo de defesa social em que a medicalização da resistência pode ocorrer pelo poder disciplinar. Caso este poder falhe na prevenção das dissidências, recorre-se ao controle biopolítico de gestão medicalizante de grupos inteiros contidos em espaços segregativos e racistas. No caso de essa modalidade ser alvo de resistência, a política de segurança deixa morrer ou mata com a medicalização, com a prática de tortura ou mesmo com a execução 
da pena capital, administrada pela morte com injeções letais aplicadas por médicos e paramédicos, por exemplo.

Desse modo, surge o anormal como o avesso ao normal, um não existindo sem o outro. O que se postula é que o processo de invenção de uma norma sempre é correlato à constituição da antinorma (Foucault, 1988).

O estatuto da anomalia passa a interessar à medicina muito mais que o da patologia, que ficaria restrito à doença. É no bojo desse deslocamento entre doença e gestão das condutas normais e anormais que a psiquiatria se generalizou para o campo social como um todo, tornando-se um saber-poder utilizado em defesa da sociedade, ou seja, como segurança, na medida em que se voltou de modo contundente ao controle dos corpos e populações desviantes.

Resistir a este modelo e/ou a ele não se assujeitar implica em ser psicopatologizado de modo rápido e acrítico. A psiquiatrização da subversão e do desvio das normas estabelecidas socialmente tem sido um ato contínuo, sobretudo nas últimas décadas do século $X X$ e início do $X X I$, com a produção exponencial de medicamentos psicotrópicos, com o aumento de síndromes e transtornos inventados nos manuais de psiquiatria e com o recrudescimento punitivo-penal, atualizado pelas sanções administradas com tecnologias educativas, médicas, psicológicas, assistenciais e de segurança.

Os discursos que visam desqualificar indivíduos pela anormalidade estão vinculados a uma rede de equipamentos, aparatos, saberes, recortes de falas e difusão de preconceitos e de táticas de controle dos dizeres e das maneiras de rotular e segmentar os corpos em instituições e por meio de regulações instrumentais de cunho histórico e econômico (Collares, \& Moysés, 1996).

A impotência política começa a andar juntamente com a violência e com a quebra de solidariedades, engendrando sentimentos de medo e de insegurança, instalados como dispositivos de subjetivação em uma sociedade que impossibilita a participação democrática e a conversação entre diferenças em seu cotidiano, para facilitar a fragilização e correlata medicalização de qualquer ato que vise questionar este modelo de sociedade.

A separação e desqualificação dos corpos por nomeações psicopatológicas em relação à prática de valorização e de desvalorização social estão ligadas aos processos racistas mediados por meio de estigmas em relação a certos grupos sociais. A desautorização da fala e dos atos é uma tentativa de os fragilizar, pressionar, silenciar e desestabilizar de maneira a deixá-los sem força política de resistência e medicalizá-los como mais um tática de desqualificação que opera para invalidar as lutas e dissidências políticas.

A sociedade moderna edificou pequenos tribunais normalizadores dos corpos, utilizando os dispositivos do exame, a sanção normalizadora e a vigilância contínua como maneira de, por meio de saberes e de poderes disciplinares e biopolíticos, julgar e classificar os corpos como normais e como anormais por meio da aproximação e do afastamento das regras sociais estabelecidas como modelos a obedecer (Foucault, 1999).
Assegurar a liberdade e a circulação pela medicalização da resistência se tornou uma forma de evitar riscos e perigos de dissidências e de rompimento com a ordem securitária estabelecida. Mesmo em instituições fechadas, com alarmes, cercas elétricas, chaves, fechaduras, grades e correntes, a medicalização se realiza para silenciar e impedir alianças subversivas e que visem questionar as práticas instituídas.

É neste sentido que observamos altos índices de medicalização em asilos, em internatos, em abrigos, em prisões, em trabalhos forçados e nas escolas. Foucault (1999) assinalou as semelhanças entre estas instituições na sociedade contemporânea. Aliás, pode-se afirmar que a análise desse autor ainda é bastante relevante para pensarmos a atualidade, pois ele nos ajuda a problematizar estes acontecimentos com vista a insistirmos na indagação e em inquietantes intervenções diante desta realidade que nos cerca e nos atravessa tão de perto.

\section{Considerações finais}

Podemos concluir que a medicalização da resistênciase tornou-se uma prática de governo em nome do cultivo da saúde, mas também um meio de organizar a população em segmentos saneados por valores individualistas e burgueses, operacionalizando uma quebra das resistências da multidão e uma disciplina docilizadora dos corpos individualizados simultaneamente, o que implicou na criação de um projeto político de defesa da sociedade paralelamente instalado como educação civilizatória e securitária marcada por tentativas de adestrar, calar, segregar, fazer trabalhar e estudar com obediência intensificada.

Desse modo, "o poder psiquiátrico, antes de ser uma cura, seria certa maneira de administrar, um regime, uma tentativa de subjugar" (Fonseca, 2002, p. 68).

Foucault (2006, p. 392-3) afirma:

A psiquiatria, nos anos 1850-1870 abandonou ao mesmo tempo o delírio, a alienação mental, a referência à verdade e, enfim, a doença. O que ela assume agora é o comportamento, são seus desvios, suas anomalias; ela toma sua referência num desenvolvimento normativo.

Este quadro é parte de uma situação mais ampla e complexa que vem ocorrendo mundialmente: a exigência de perfomances cada vez mais competitivas, individualistas e pouco críticas, marcadas por rápidas capturas em discursos biologizantes como racionalidade explicativa dos desvios e divergências nas relações e em relação às normas - que hoje são pouco negociadas no plano das sociabilidades. Assim, a medicalização entra na esfera do mercado da saúde para dificultar resistências e ampliar o capital humano, mas pode ser acionada para efetuar a segurança de cunho punitivo e de caráter penal-retributivo, aplicando até a pena de morte, se a resistência for ampliada. 
A intensidade cada vez maior de encomendas de competição no trabalho e de exigências altíssimas de desempenho por metas, somada ao esgarçamento da solidariedade e à fragmentação dos laços sociais, cria espaço para a ampliação da medicalização dos corpos. Situações que possam diminuir as capacidades e ou torná-las mais lentas ou excessivamente rápidas a ponto de prejudicar as performances e qualquer movimento de resistência à lógica consumista e de mercado de cada ato cotidiano são rapidamente medicalizados.

Finalizando, podemos afirmar que vivemos em uma sociedade que não aceita o sofrimento, o choro, a tristeza, a crítica, a fala subversiva, a dissidência, e que reitera uma ilusão de felicidade, de alto desempenho e de saúde como salvação idealizada, em uma verdadeira subjetividade biomedicalizada e empresarial em que o uso de fármacos e da racionalidade medicalizada se tornou uma estratégia disciplinar e biopolítica de existência normalizada que tenta calar qualquer ato mínimo de resistência, mesmo que tenha que fazer morrer.

\section{Referências}

Boarini, M.L. (2003). Higiene e Raçacomo projetos: higienismo e eugenismo no Brasil. Maringá: EDUEM.

Castel, R. (1987). A gestão dos Riscos: da antipsiquiatria à póspsicanálise. Rio de Janeiro: Francisco Alves.

Collares, C. A. L., \& Moysés, M. A. A. (1996). Preconceitos no cotidiano escolar: ensino e medicalização. São Paulo: Cortez.
Donzelot, J. (1986).A polícia das famílias. Rio de Janeiro: Paz e Terra.

Fonseca, M. A. da (2002).Michel Foucault e o Direito. São Paulo: Max Limonad.

Foucault, M. (1988). História da sexualidade: a vontade de saber. Rio de Janeiro: Graal.

Foucault, M. (1999). Vigiar e punir: a história da violência nas prisões. Petrópolis: Vozes.

Foucault, M. (2004) A evolução da noção de indivíduo perigoso na psiquiatria legal do século XX. Em Foucault, M. Ética, sexualidade, política. Rio de Janeiro: Forense.

Foucault, M. (2006) O poder psiquiátrico. São Paulo: Martins Fontes.

Foucault, M. (2008a) Segurança, território e população. São Paulo: Martins Fontes.

Foucault, M. (2008b) Nascimento da biopolítica. São Paulo: Martins Fontes.

Foucault, M. (1979).Microfísica do poder. Rio de Janeiro: Graal.

Souza, M. P. R. (2010). Retornando à patologização para justificar a não aprendizagem escolar: a medicalização e o diagnóstico de transtornos de aprendizagem em tempos de neoliberalismo. Em Conselho Regional de Psicologia de São Paulo e Grupo Interinstitucional Queixa Escolar (Orgs.) Medicalização de crianças e adolescentes: conflitos silenciados pela redução de questões sociais à doença de indivíduos (pp. 57-67). São Paulo: Casa do Psicólogo.

\section{Sobre a autora}

Flávia Cristina Silveira Lemos (flaviacslemos@gmail.com)

Profa. Adjunta III em Psicologia Social/UFPA. Coordenadora do Programa de Pós-graduação em Psicologia/UFPA. Psicóloga, Mestre em Psicologia e Sociedade e Doutora em História e Sociedade/UNESP-Assis/SP. 